\section{Notes on the breeding of Hottentotta pachyurus Pocock, 1897 (Scorpiones: Buthidae)}

\author{
Zeeshan Mirza $^{1}$, Kunal Ullalkar ${ }^{2}$ \& Gavin Desouza ${ }^{3}$ \\ 11-13 Shiv Colony, Marol Police Camp, Andheri (East), Mumbai, \\ Maharashtra 400059, India \\ ${ }^{2}$ Row House no. 16, Customs Colony, Military Road, Marol, \\ Andheri (East), Mumbai, Maharashtra 400059, India \\ ${ }^{3}$ 8/6/9 Bhavani Nagar, Marol Maroshi Road, Andheri (East), \\ Mumbai, Maharashtra 400059, India \\ Email: ${ }^{1}$ snakeszeeshan@gmail.com
}

Buthidae Koch, 1837 is one of the largest scorpion families with 82 genera (including one extinct) and 773 species having a tropical, subtropical, and partly temperate distribution, notably absent in Antarctica and New Zealand. Members of the family are of special interest due to their medical importance. Some genera from this family, for example Androctonus, Centruroides, Hottentotta, Leiurus, Parabuthus and Tityus are lethal to man. They are small to medium-sized scorpions averaging $20 \mathrm{~mm}$ to $120 \mathrm{~mm}$ in length (Rein 2006). Despite their widespread distribution, members of the Buthidae family are poorly understood in terms of natural history and ecology. Hottentotta, earlier described as a subgenus, is one of the most widely distributed genera, with species present throughout Africa, the Arabian peninsula, and Asia including Pakistan and India (Kovaøík 2007).

Hottentotta pachyurus was initially described as Buthus pachyurus and was later assigned to the genus Mesobuthus by Tikader \& Bastawade (1983). Kovaøík (2007) in his revision of the genus Hottentotta transferred M. pachyurus to Hottentotta. It is a widely distributed species occurring at Sangli, Sholapur, Satara, Poona, Aurangabad and Nasik in the state of Maharashtra in India (Tikader \& Bastawade 1983). GourBroome \& Zambre (2007) reported H. pachyurus to be found in wood, lofts, tree trunks, and roofing timbers, and as having a painful sting.

Date of publication 26 March 2009

ISSN 0974-7907 (online) | 0974-7893 (print)

Editor: Vinod Khanna

\section{Manuscript details:}

Ms \# 01980

Received 19 April 2008

Final revised received 28 August 2008

Finally accepted 15 October 2008

Citation: Mirza, Z., K. Ullalkar \& G. Desouza (2009). Notes on the breeding of Hottentotta pachyurus Pocock, 1897 (Scorpiones: Buthidae). Journal of Threatened Taxa 1(3): 186-187

Copyright: @ Zeeshan Mirza, Kunal Ullalkar \& Gavin Desouza 2009. Creative Commons Attribution 3.0 Unported License. JoTT allows unrestricted use of this article in any medium for non-profit purposes, reproduction and distribution by providing adequate credit to the authors and the source of publication.

Acknowledgements: We wish to thank Amod Zambre for providing us with impossible-to-find literature and helped with useful comments; and Jan O. Rein, Sunny Patil, Mihir Sule and Mittal Gala. We also wish to thank the anonymous reviewers for their constructive comments.

OPEN AGCESS | FREE DOWNLOAD
On 9 May 2007 we collected a live specimen of a female scorpion identified as Hottentotta pachyurus (Image 1) from near Karla caves, Lonavala, Maharashtra from under a boulder with Hemidactylus cf. brookii (Reptilia: Gekkonidae) being one of the sympatric species. The scorpion was black with the tarsus of the pedipalps distinctively reddish-brown; measuring ca. $25 \mathrm{~mm}$ in total length.

The live scorpion was housed in a plastic box, the substrate of which was comprised of loose soil and bark pieces, and mealworms were introduced into the box for it to feed upon. The scorpion would hold the mealworms between its pedipalps, sting them, and then proceed to consume them once they were paralyzed. The scorpion grew to about $41.76 \mathrm{~mm}$ with a distinctly bulging mesosoma. On 22 January 2008 at $2230 \mathrm{hr}$ the scorpion was observed in the corner of the box and on 23 January 2008 at $1100 \mathrm{hr} 16$ hatchlings were observed on its back. The newly born young had dark rufous carapaces and mesosomas, with light colored legs that contrasted with their metasomas and pedipalps, which were a shade of orange. As they grow, the entire body color changes to dark brownishblack ultimately changing to overall black at adulthood. GourBroome \& Zambre (2007) reported juvenile Hottentotta pachyurus to have a reddish body and black legs. By 24 January 2008 three of the juveniles were found dead and were later consumed by their siblings. By 25 January most of the juveniles had abandoned their mother, molted, and were observed feeding upon their exoskeletons (Images $2 \& 3$ ). The juveniles ranged in size from 7.02 to $10.70 \mathrm{~mm}$ and were active and alert, stinging at the slightest provocation. Later they were released at the site where the adult female was collected. During the prolonged gestation period of eight months and 13 days (under observation), the female did not molt. When the female was collected, she did not show any signs of aggression, but as the time of parturition approached she would get agitated and sting at the slightest provocation.

Members of the family Buthidae are known to have a minimum gestation period of 1 month (Orthochirus innesi Simon) and a maximum gestation period of 10 months (Buthus occitanus Amoreux). Litter sizes vary from 5 to 105 (Polis 1990). Hottentotta pachyurus is presently reported to have a gestation period exceeding eight months and 13 days under laboratory conditions as mating did not occur in captivity.

During the period of captivity an individual of Hottentotta tamulus Fabricius 1798 was introduced (in the month of June 2007) into the housing box, agitating the female H. pachyurus. As $H$. tamulus entered into the striking range of $H$. pachyurus it was repeatedly stung, and after stinging $H$. pachyurus once, immediately retreated into a corner. The scorpions were separated after this incident. The H. tamulus was retained and observed for a week after being stung and was then released. No sign of envenomation was evident in the form of abnormal behavior or swelling.

Since mating did not occur in captivity we assume that $H$. pachyurus might be parthogenic, similar to two other species of the genus Hottentotta namely, H. hottentotta and H. caboverdensis (Lourenço \& Ythier 2007; Lourenço et al. 2007) but this needs further investigation. Lourenço et al. (2007) mentions 10 species of the family Buthidae to be parthogenic, namely Tityus serrulatus, Tityus uruguayensis, Tityus columbianus, Tityus trivittatus, 


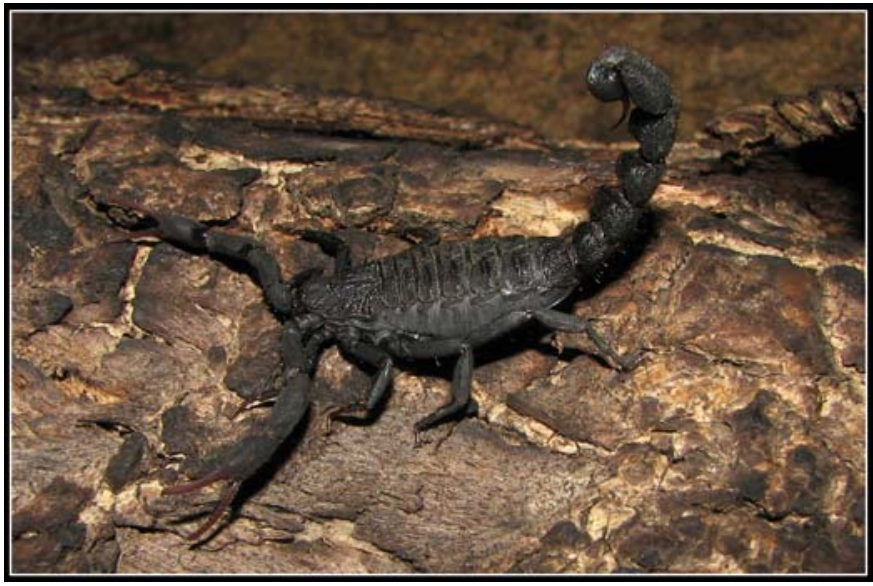

Image 1. Hottentotta pachyurus female before giving birth

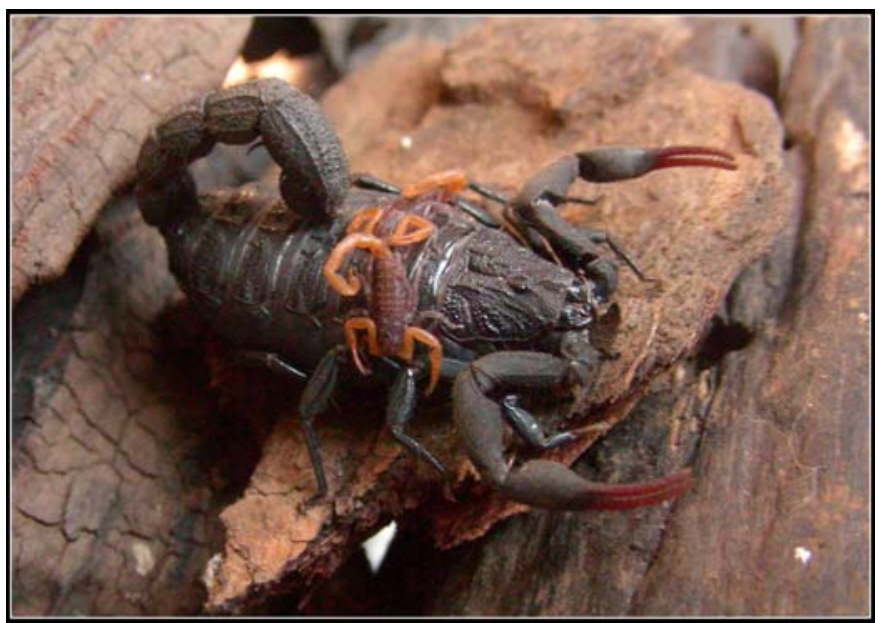

Image 2. Hatchlings of Hottentotta pachyurus on mother

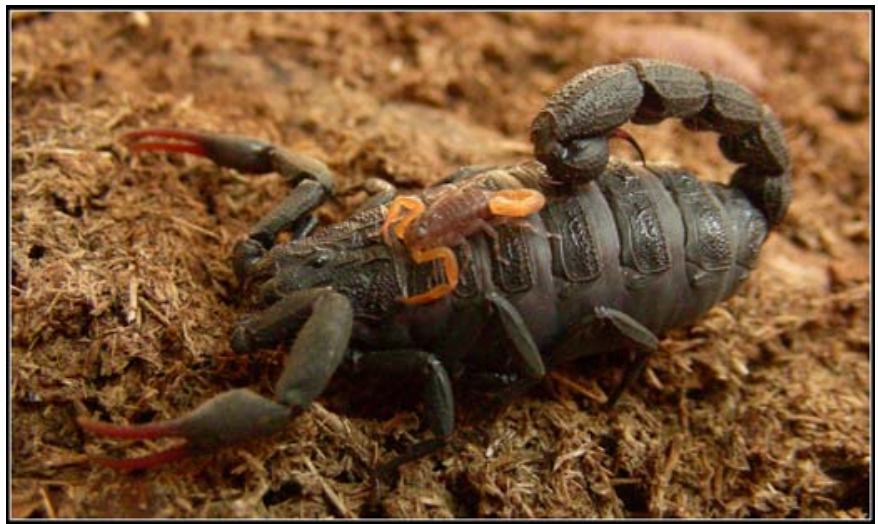

Image 3. Hottentotta pachyurus female with juvenile

Tityus stigmurus, Tityus metuendus, Ananteris coineaui, Centruroides gracilis, Hottentotta hottentotta and Liocheles australasiae. During a survey in an area less than $1 \mathrm{~km}^{2}$ at Pune, only two males in a total of 30 specimens of Hottentotta tamulus were observed (Amod Zambre pers. comm.). This indicates that the sex ratio of females to males may be high. A further detailed study is required to ascertain parthenogenesis in Indian scorpions.

Most of the work pertaining to Indian species of scorpions has dealt with the toxicity of their venom. Thus this report on
Table 1. Morphometry of the captive adult female Hottentotta pachyurus from 21 February 2007

\begin{tabular}{ll}
\hline Characters & $\mathbf{m m}$ (Length/Width/Depth) \\
\hline Total Length & 50.26 \\
Carapace & 6.06 \\
Mesosoma & 21.06 \\
Metasoma & 23.14 \\
Metasomal Segment I & $3.14 / 4.16$ \\
Metasomal Segment II & $4.78 / 4.04$ \\
Metasomal Segment III & $3.44 / 4.06$ \\
Metasomal Segment IV & $4.20 / 4.82$ \\
Metasomal Segment V & $5.54 / 4.72$ \\
Telson & 6.78 \\
Vesicle & $4.80 / 3.60 / 3.70$ \\
Femur & $5.10 / 1.40$ \\
Patella & $6 / 3.50$ \\
Chela & 10.34 \\
Palm & $4.18 / 2.20 / 2.22$ \\
Movable Finger & $6.82 / 6.86$ \\
Leg II Coxa & 2.3 \\
Leg III Coxa & 6.6 \\
Leg IV Coxa & 4.8 \\
Sternum & 1.18 \\
Anterior/Posterior Width & 1.08 \\
Apex Lateral Side Length & $0.60 / 1.68$ \\
Pectinal Teeth & $21 / 22$ \\
\hline & \\
\hline & \\
\hline &
\end{tabular}

the breeding biology of Hottentotta pachyurus adds some information on the natural history and ecology of this little known buthid.

\section{References}

Gour-Broome, V. \& A. Zambre (2007). Sting in the tail, scorpion vignettes from Maharashtra. Sanctuary Asia XXVII(1): 60-65.

Kovaøík, F. (2007). A revision of the genus Hottentotta Birula, 1908, with descriptions of four new species (Scorpiones, Buthidae). Euscorpius - Occasional Publications in Scorpiology, 58: 1-107.

Lourenço, R.W. \& E. Ythier (2007). Confirmation of reproduction by parthenogenesis in Hottentotta hottentotta (Fabricius) (Scorpiones, Buthidae). Acta Biologica Par., Curitiba, 36(3-4): 213-217.

Lourenço, R.W., E. Ythier \& J.L. Cloudsley-Thompson (2007). Parthenogenesis in Hottentotta caboverdensis Lourenço \& Ythier, 2006 (Scorpiones, Buthidae) from the Cape Verde islands Boletin Sociedad Entomológica Aragonesa n 1 41: 193-196.

Pocock, R.I. (1900). The Fauna of British India, including Ceylon and Burma. Arachnida. Taylor and Francis, London, 279pp.

Polis, G.A. (ed.) (1990). The Biology of Scorpions. Stanford University press, Stanford, May, 233pp.

Rein, J.O. (2006). The Scorpion Files. Norwegian University of Science and Technology, online at http://www.ub.ntnu.no/scorpion-files.

Tikader, B.K. \& D.B. Bastawade (1983). Scorpions (Scorpionida Arachnida). In: The Fauna of India Vol. 3. Zoological Survey of India, Calcutta, $671 \mathrm{pp}$. 